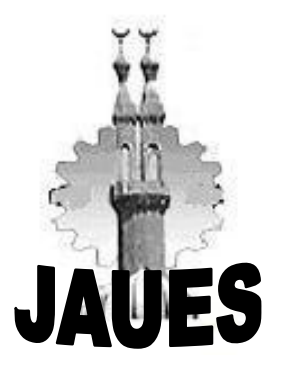

Journal of Al Azhar University Engineering Sector

Vol. 13, No. 48, July 2018, 1016-1030

\title{
ECONOMICALLY OPTIMAL DESIGN OF HYBRID RENEWABLE ENERGY SYSTEMS USING HOMER AND ACO
}

\author{
Nagger Hassan, Khaled Abd El_Atey and Amr Hosny Mohammed El_Enany \\ Electrical Power and Machines Department Faculty of Engineering Ain Shams University
}

\begin{abstract}
A B S T R A C T
Today, the growing energy demand has shaped dramatic depletion of fossil fuels and unavoidable rising energy values. Furthermore, environmental effect of fossil fuel led to vital for using Renewable Energy (RE) to meet the increasing energy demand and resolve the emission problems. Irregularity and the high price of the renewable energy technologies are the key challenges of renewable energy usage. This approach presents an arranged examination for optimum pattern of Hybrid Renewable Energy Systems (HRES). The optimization was appreciated through the usage of Hybrid Optimization Model for Electric Renewable (HOMER) program and Ant colony optimization (ACO) algorithms in MATLAB is existing in this study. The recommended methodology has been proven on an incident study of an HRES that includes wind turbine, photovoltaic (PV) panels, natural gas generator and batteries. In conclusion, HRES design via a multi-impartial optimization source. The main purpose of the design is to promptly reduce total Net Present Cost (NPC), maximize renewable energy quotient, and decrease fuel emission.

Additionally ACO algorithms not common usage in similar renewable energy studies which give advantage and make this study pioneer in this field, Also give more accurate results compared with HOMER program that shows in this paper.
\end{abstract}

\section{INTRODUCTION}

Energy is an important requirement for all social events, manufacture of all goods and the establishment of all services. Then, energy is also and still to be the biggest disaster to human beings, meanwhile currently the common of the energy that had been used on earth approaches from conventional fossil fuel. Approximately of these fuels will be exhausted in some ages according to the latest exploring and consuming rate. Furthermore, there are still about 1.5 billion populations worldwide still having no admission to electricity [1-2]. The electrical energy is normally powered by diesel generators. Conversely, they felt more and more worried meanwhile they often face inordinate fuel costs due to huge rise in diesel cost and extra costs of delivery. Moreover, the harmful environmental effects from the occupation of diesel damage the local environmental system and cause noise, water, soil and air pollution [3]. In the subject, they undergo from energy shortage or blackouts frequently.

The power supply by renewable systems is today becoming reasonable with conventional energy. This inspiring leads to widely employment of Renewable Energy Systems (RES) for off-grid power supply, such as PV/battery, wind/battery, PV or wind based pumped storage, or hybrid 
renewable systems [4-10]. Until now, research on RES is usually carried out in the fields of system molding, simulation, component sizing, economic analysis, and particularly system optimization [11-16]. To carry out these researches, the simulation models and computer tools are usually required. Perfectly 37 computer tools for analyzing the RES has been revised in [17], and a review of approach of optimizing the hybrid RES was approved in [18]. Between the simulation tools, HOMER software is one of the most frequently used for separate RES [19]. This software can support in the design of micro grid systems and simplify the link of power generation technologies across an extensive range of applications [20]. Using HOMER for RES displaying, reproduction and economically breakdown has been the focus matter of considerable earlier studies.

Alternatively the public insects like ants, bees and termites work by themselves in their modest tasks, individually of others associates of the colony. Though, when they act as a community, they are able to solve complex problems developing in their daily lives, by means of conjoint cooperation. This developing performance of a group of social insects is known as 'Swarm intelligence' [21]. Ants are able to find the shortest route between a food source and the nest without the support of visual info, and also to adjust to a varying environment [22]. It was recognize that the manner ants interconnect with each other through pheromone streams. However ants move, they drop a definite amount of pheromone on the ground, leaving behind a trail of this material that can be monitored by further ants. The more ants shadow a pheromone stream, the more attractive the trail develops to be followed in the near future. The basic idea is shown in Fig. 1.

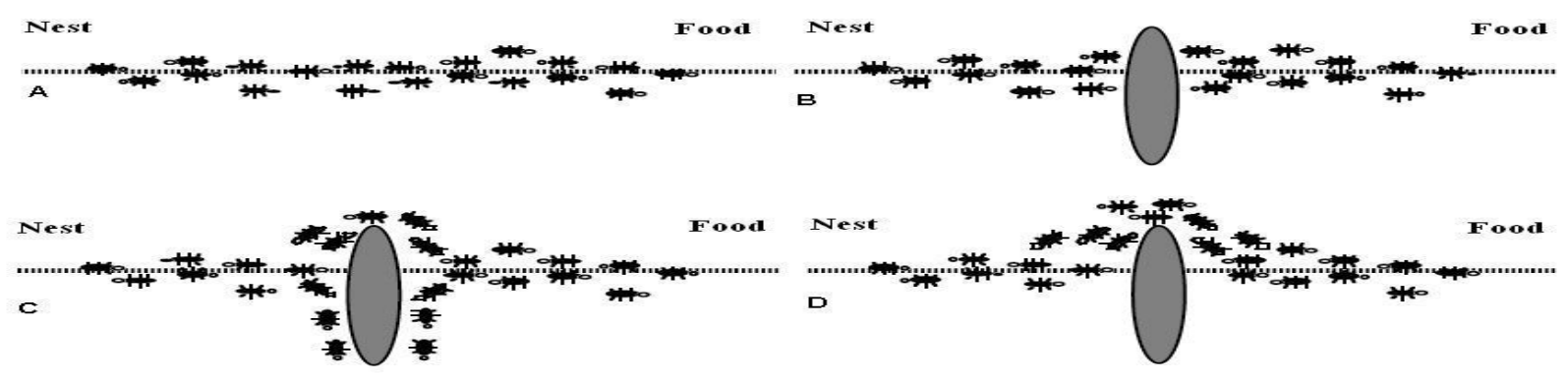

Fig 1. Ant Colony Technique

The perseverance of this study is to find the best mixture of hybrid renewable energy system from the existing resources in a given location that can meet the electricity demand in a consistent and maintainable manner. Likewise, the proposed of this study is to analyze whether such a hybrid choice is a cost active solution or not. The hybrid system, which contains a PV array, wind turbines, batteries and generators, is calculated to be able to achieve the main load for the nominated area. The planned hybrid Micro Grid (MG) is modeled, improved and simulated using HOMER program, And ACO optimization based on lower Net Present Cost (NPC) method. Furthermore, optimization grades, price summary, and emission are analyzed. Lastly, the compassion results and payback period are conversed in this study.

\section{SITE DESCRIPTION}

Position of the grids $\left(30^{\circ} 1^{\prime} 48^{\prime \prime} \mathrm{N}, 31^{\circ} 46^{\prime} 48^{\prime \prime}\right.$ E) that located on Cairo Suez road this grid will be the main power source for the new administrative capital that is the vision for new Egypt Fig. 2,3. The renewable energy is the first step in the sustainability for Egypt which be the first country in the Middle East and Africa in this field. Where this station is the beginning of a new era in economic openness and cancel the monopoly in the field of electricity and also contribute to the increase in the productivity of renewable energy and the exploitation of wasted resources 


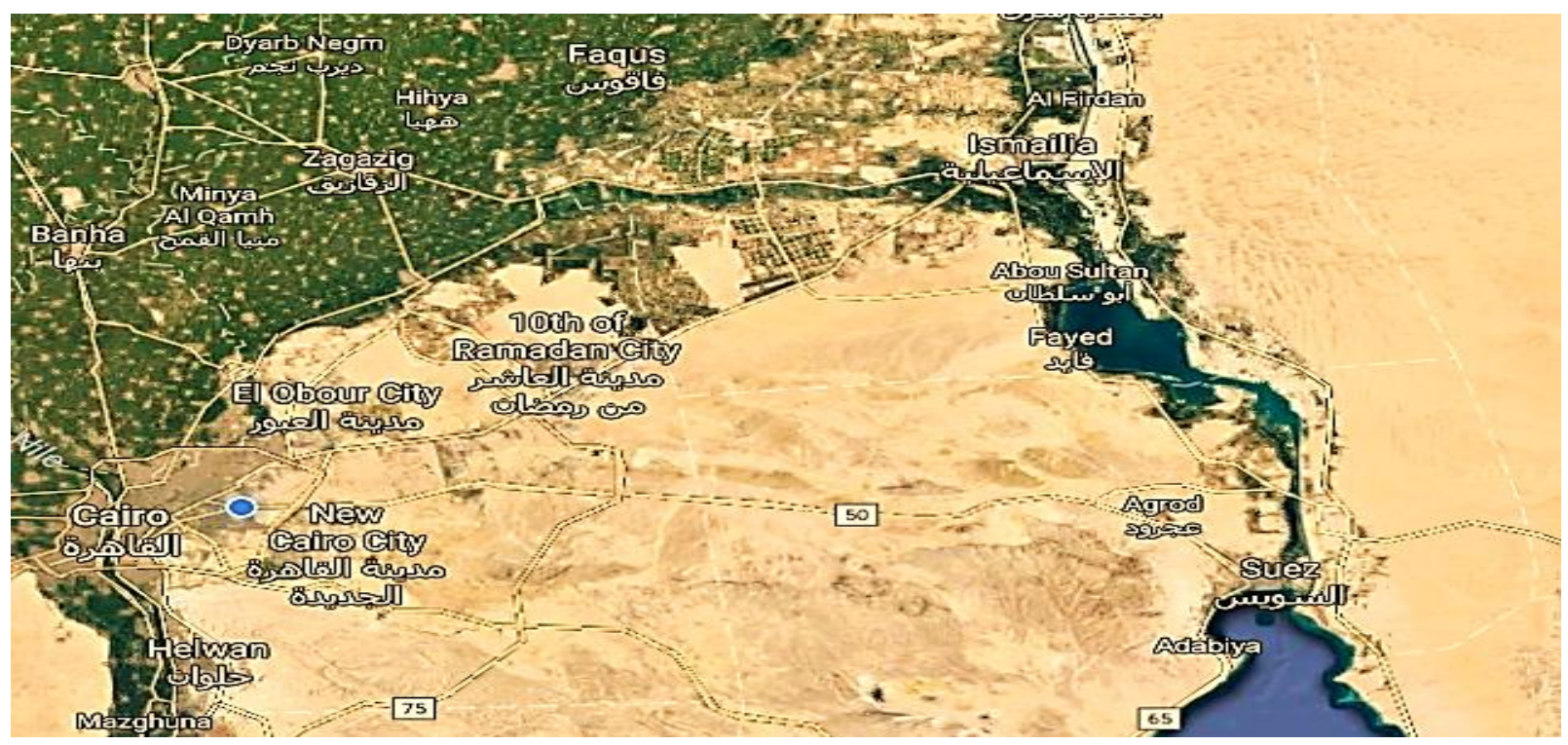

Fig 2 New Capital /Egypt

\section{Optimization using HOMER}

\section{Wind Data}

Wind source data are essential data to define the wind states that wind turbine would exercise in a typical year. The most vital wind source data is the wind speed that should be providing as monthly average. Alternative obligatory constraint to proposal the wind system is recognized as Weibull shape factor. This constraint is a degree of the supply of wind speeds over the year. Really, this feature shows how windy a location is. The third constraint is baptized "autocorrelation factor". This degree shows how strongly the wind speed in 1 hour inclines to depend on the wind speed in the earlier hour. The fourth factor is definite as "diurnal pattern strength". This factor displays how strongly the wind speed inclines to trust on the time of the day. The additional feature is hour of peak that is the hour of the day where inclines to be windiest. Development of the place above the sea level is also another limit essential to calculate the density of the air desired in wind turbine output power controls. The last necessary parameter is anemone meter height, presentation the heights above the ground wherever the wind speed data are measured. The monthly average wind speed at Cairo [23] this shown in fig 3. However the average wind speeds are not high enough for wind farm, they are suitable for wind-hybrid systems and the turbine which is nominated carefully to be suitable for wind speed in this location and will explain in details next papers $(5,6)$.

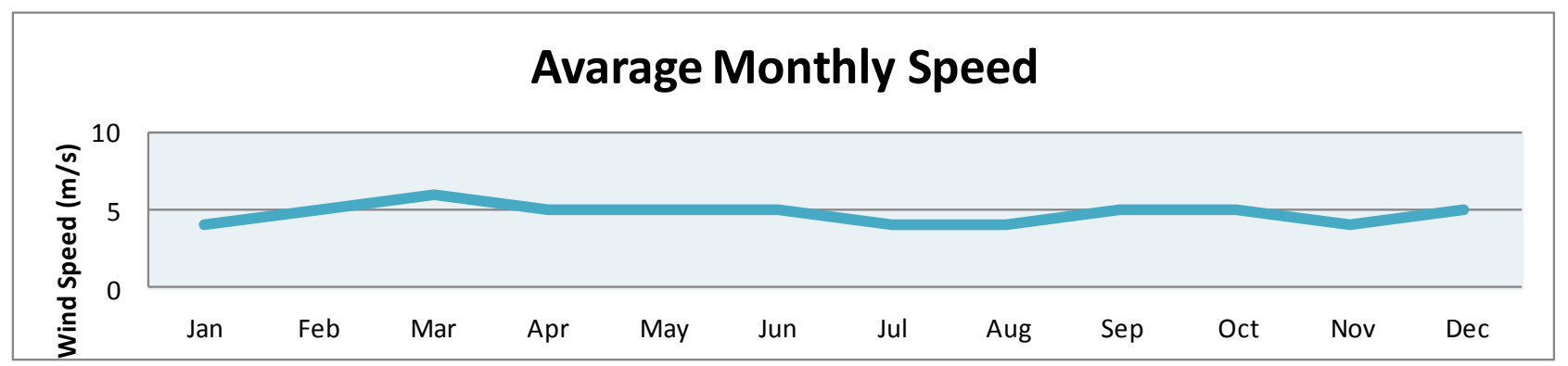

Fig 3. Monthly average wind speed. 


\section{Solar Data}

The amount of solar radiation in a typical year is reachable as daily average global solar radiation in the horizontal surface $\left(\mathrm{kWh} / \mathrm{m}^{2}\right.$ day). This amount is achieved by addition of beam radiation that creates straight from the sun, to diffusion radiation impending from all portions of the sky.The clearness of the air is exposed by a constraint known as clearness index. It shows the ratio of the solar radiation striking earth's surface to the solar heat striking the top of the sky. The solar radiation that spreads to earth surface is fewer than the radiation striking the top of the atmosphere since of humidity, dust, clouds, or even temperature variations in the lower thermosphere [24]. Solar data for the selected location is exposed in Fig. 4. It should be note that March and August has the highest daily radiation while the lowest radiation occurs during December [24].

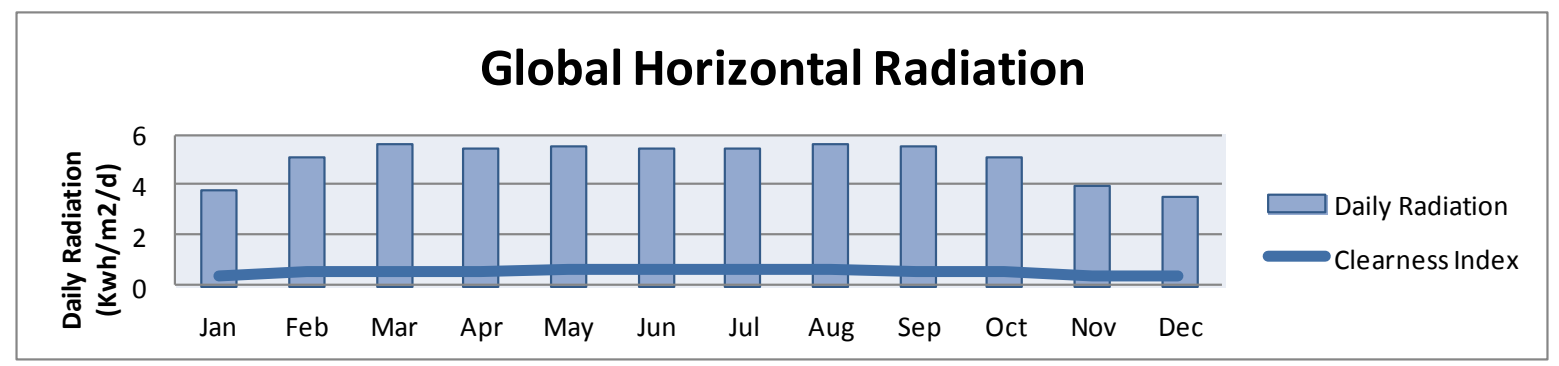

Fig 4. Eastern Cairo horizontal radiation and clearness index.

\section{Electrical load data}

This study is achieved based on average primary load, which is $11 \mathrm{MW}$ to be able to fulfill the primary load for new projects in the mentioned location above. It is estimated that this part of load data follow the load model of other sites at nominalized location where the grid is accessible. The load specifics exposed in table 1, also the monthly average load for annual averages shown in Fig.5.

Table 1. Electrical Load data

\begin{tabular}{|c|c|}
\cline { 2 - 2 } \multicolumn{1}{c|}{} & Baseline \\
\hline Average $(\mathbf{k W h} / \mathbf{d})$ & 83,208 \\
\hline Average $(\mathbf{k W})$ & 3,467 \\
\hline Peak $(\mathbf{k W})$ & 10,719 \\
\hline Load factor & 0.323 \\
\hline
\end{tabular}

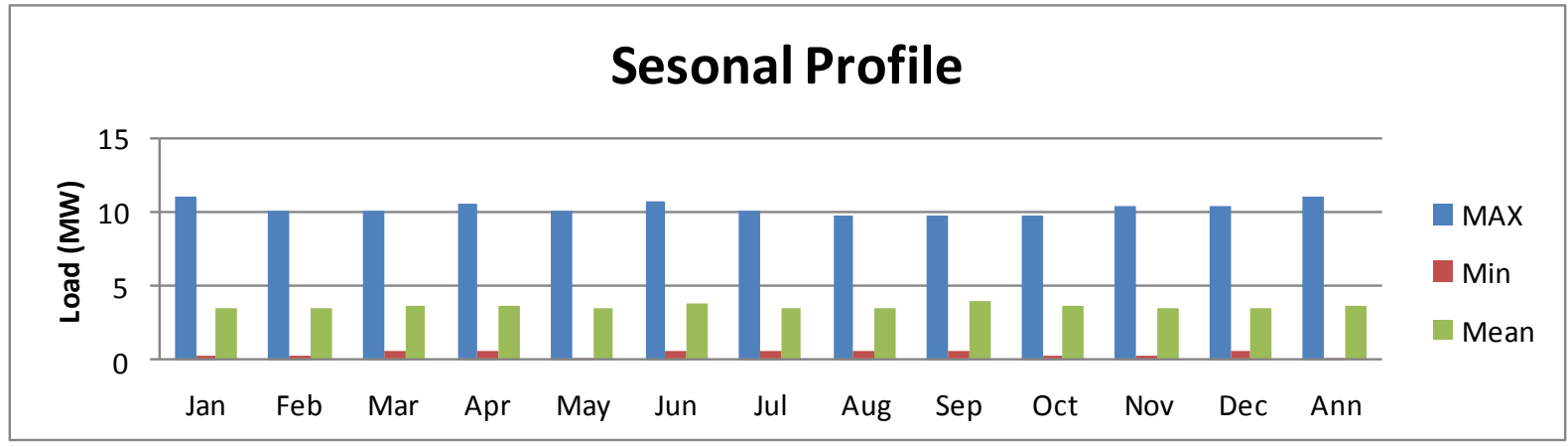

Fig 5. Monthly average load for annual averages. 


\section{HYBRID SYSTEM COMPONENTS}

The suggested hybrid system contains renewable sources, natural gas generators and storage batteries. The core renewable sources for generating power at our study are photovoltaic arrays and wind turbines. Natural gas generator is used as dispatch able energy at this study to recompense power in the lack of renewable source. The batteries can feed electricity into the system in the lack of renewable sources and also can store excess energy once the power from the renewable sources is additional. Fig. 6. Demonstrate the typical separate grid too, the impact percentage for each component shown in Fig. 7. Explanation and details of the hybrid system modules are given in the subsequent parts.

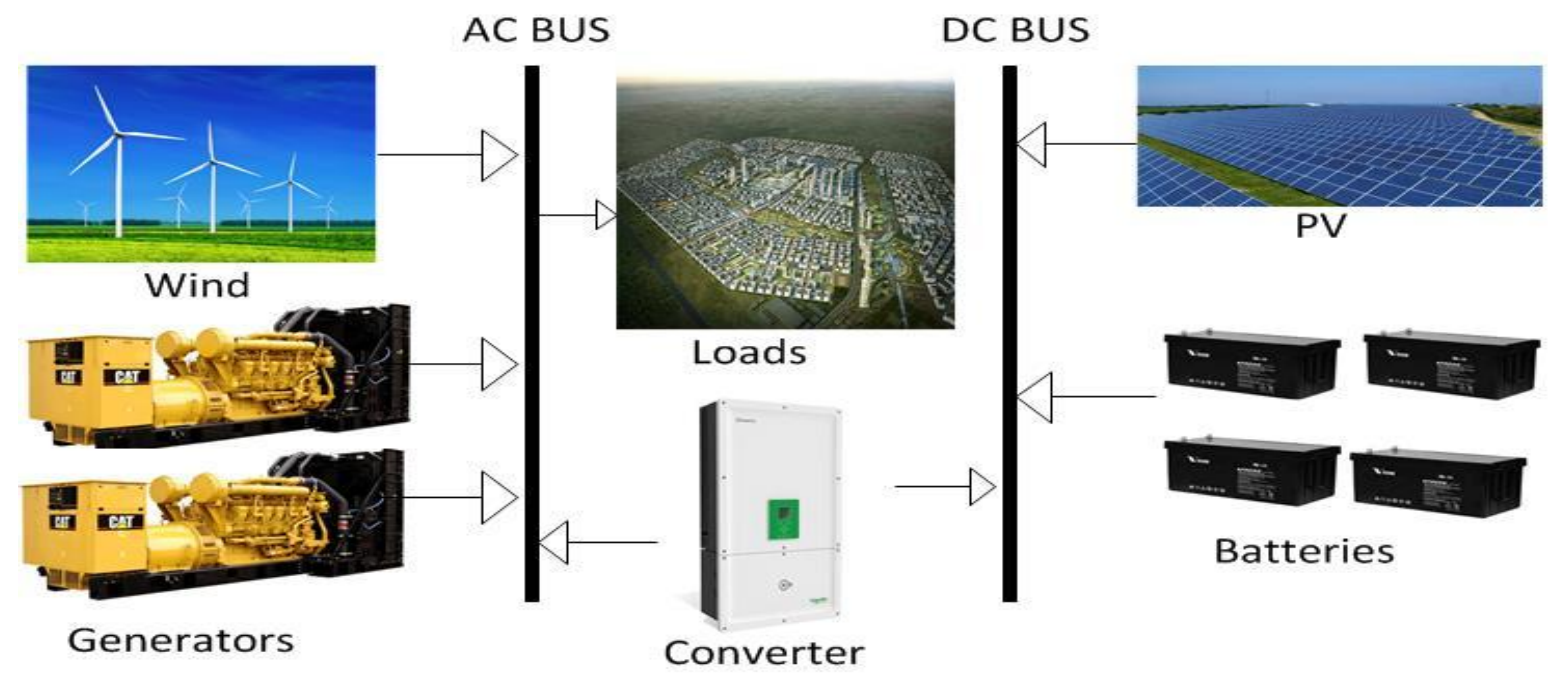

Fig 6. Typical stand-alone hybrid system.

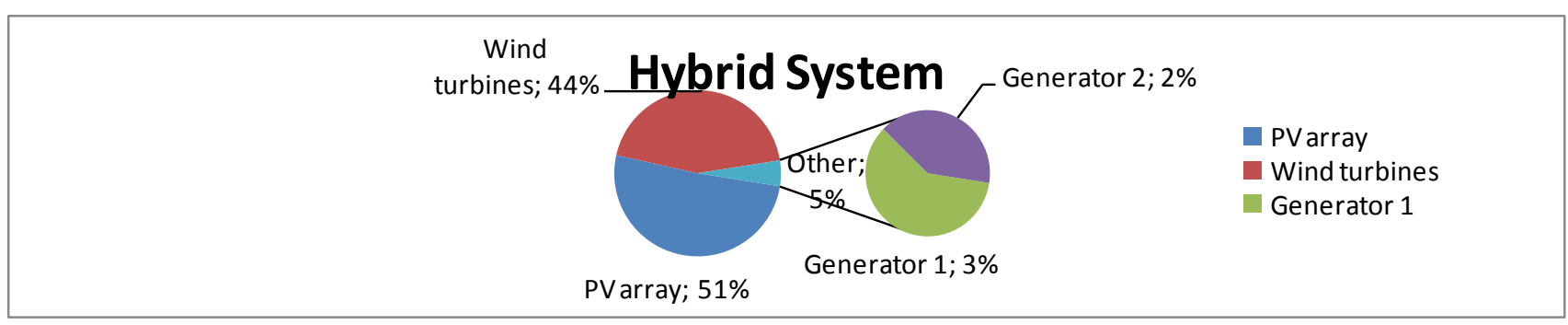

\subsection{PV panels}

Fig 7. Hybrid System Role

The output power of an arrays can be designed using equations and manufacturer specifications. It can be estimated that array's power output is linearly related to the amount of the solar radiation attainment the panels. The system didn't prepared with Maximum Power Point Tracking (MPPT) system. MPPT is an electric device used by solar battery supports and grid link converters in order to get the maximum probable power from solar panels. Maximum Power Point (MPP) is the operational point at which the output current and output voltage result in an output power from the cell which is maximum for a specified irradiance or cell temperature. Table. 2 shows the official technical data for the PV array. 
Table 2

\begin{tabular}{|l|c|}
\hline \multicolumn{2}{|c|}{ TOPSUN } \\
\hline \multicolumn{2}{|c|}{ Polycrystalline 3 Bus bar [96 cells] } \\
\hline Model & TS-M400 \\
\hline Power Output (W) & 400 \\
\hline Open Circuit Voltage (V) & 60.4 \\
\hline Short Circuit Current (A) & $\mathbf{8 . 5 9}$ \\
\hline Efficiency (\%) & 15.6 \\
\hline Weight (kg) & 35 \\
\hline
\end{tabular}

\section{PV Panel specification.}

\section{2. Wind turbines}

The wind turbine used in this approach is nominated to be able to achieve all ranges of loads. The wind turbine is GE 1.5 sle with $1.5 \mathrm{MW}$ rated power that is a three blade wind turbine made by general electric company. GE 1.5 sle is boosted for low and medium wind conditions. Table. 3 and Fig. 8 show GE1.5sle specifications and power curve, correspondingly.

Table 3. Wind turbine specification.

\begin{tabular}{|l|l|}
\hline \multicolumn{2}{|c|}{ Technical data } \\
\hline \multicolumn{2}{|c|}{ GE 1.5sle } \\
\hline Operating Data & $1,500 \mathrm{~kW}$ \\
\hline Rated Capacity & $3.5 \mathrm{~m} / \mathrm{s}$ \\
\hline Cut-in Wind Speed: & $25 \mathrm{~m} / \mathrm{s}$ \\
\hline Cut-out Wind Speed (10 min avg.): & $14 \mathrm{~m} / \mathrm{s}$ \\
\hline Rated Wind Speed: & \multicolumn{2}{|l|}{} \\
\hline Electrical Interface & $50 / 60 \mathrm{~Hz}$ \\
\hline Frequency & $690 \mathrm{~V}$ \\
\hline Voltage & \multicolumn{2}{|l}{} \\
\hline Rotor & $77 \mathrm{~m}$ \\
\hline Rotor Diameter: & $4657 \mathrm{~m} 2$ \\
\hline Swept Area: & $65 / 80 \mathrm{~m}$ \\
\hline Tower & \multicolumn{2}{|l}{} \\
\hline Hub Heights: & Active Blade \\
\hline Power Control & Pitch Control \\
\hline
\end{tabular}

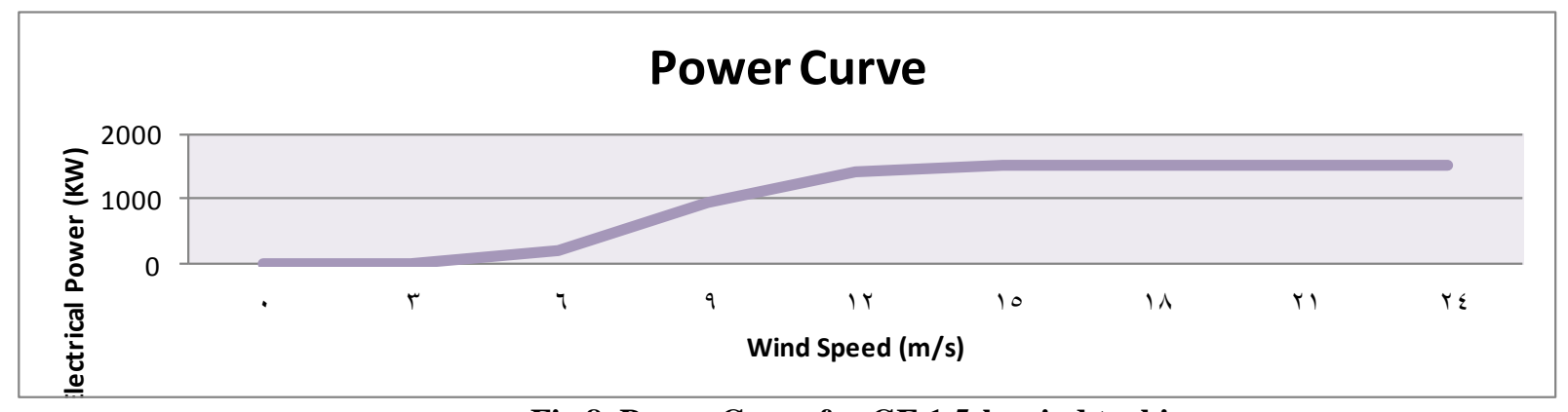

Fig 8. Power Curve for GE 1.5sle wind turbine. 


\subsection{Natural Gas Generator}

It plays important role in conventional plants. However it is considered a sub-factor or unessential or unnecessary for the hybrid renewable plants. And expendable, but is used only in certain cases In the case of loads reached a certain margin play an economic role in the meantime, i.e. wherever it is inexpensive than the use of renewable source, And also in the case of shortage in any renewable sources used for covering the load demand .Finally, the natural gas generator considered here mechanism as a standby energy source, i.e. the system can turn the generator on as essential, in this approach we use natural gas generators instead of diesel due to Egypt has a plenty of natural gas and the second motive lower emission than diesel generators.

The selected natural gas generator is Cater pillar series with specifications as shown in Table 4. The fuel consumption versus output power is given in Fig.9.

Table 4 . Natural GAS Generator Set Specification

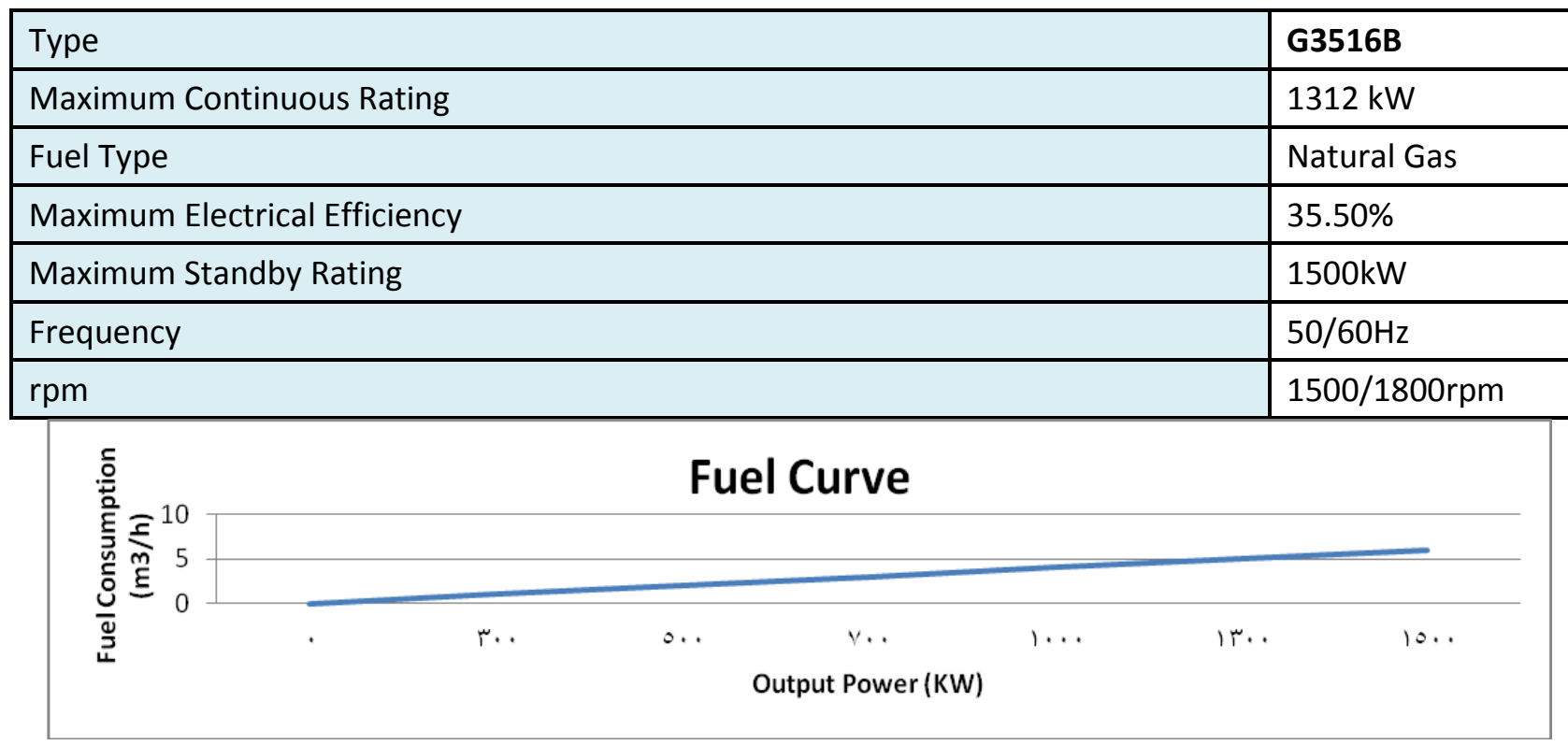

Fig 9. Natural gas generator fuel curve

\section{COMPONENTS COST AND ECONOMIC ANALYSIS}

In this approach the software chooses the optimized system conformation based on the minimum total NPC. NPC is the rate of a scheme throughout the entire project period which is 25 years in this study. The NPC contains different prices such as the value of initial structure, operation and maintenance, replacement, fuel, salvage, drawbacks due to the emissions, etc. Salvage cost is called to the remaining value of a module at the termination of the project lifespan.

The NPC is calculated by equation (1) [25]:

$$
\text { CNPC }=\text { Cann, tot } \underset{i}{-} \operatorname{CRF}(i, R \text { proj })
$$

CRF (i, Rproj): Capital recovery factor is a ratio used to define the present value of an income. It can be estimated using equation (2) [54]:

$$
\operatorname{CRF}(\mathbf{i}, \mathbf{N})=[\mathbf{i}(\mathbf{1}+\mathbf{i}) \mathbf{n}] /[(\mathbf{I}+\mathbf{i}) \mathbf{N}-\mathbf{1}]]
$$

i: Yearly real attention rate. It is the reduction rate used to convert between one-time costs and annualized costs. Drop of interest rate reasons reduction of capital recovery factor and leads to bigger NPC. 
$\mathrm{N}$ : The number of years, 25 years at present study

Cann,tot: Total annualized cost, is the sum of the annually budgets of each system component. The annual cost of an element is equivalent to its annual operating budget and above its capital and replacement costs annualized over the project lifetime. Costs can be shown in terms of annualized and net present. The cost summary contains capital, replacement and Operation costs of all components, fuel costs and salvage cost. The major share of cost is for the fuel at this approach due to high growth rate of fuel price during recent years.

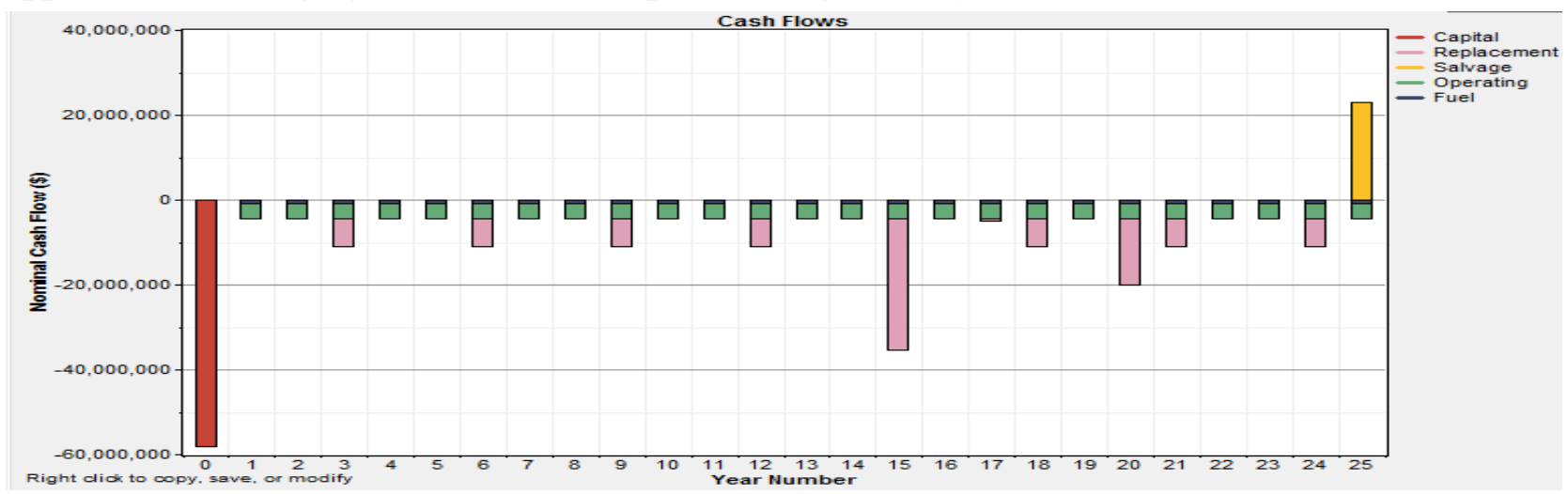

Fig 10. Cash Flow Chart

We notes from the present chart the capital cost of the project is $\$ 58$ million, every year we note also the operation cost (Operation, Maintenance and Fuel) is constant until the project lifetime. Likewise the replacement of the batteries is extra each 3 years. In the year 15 of the development the replacement cost for the wind turbine is appear on the chart, also at year 20 the replacement value for the PV is additional till reach to the end of the project and the salvage value appear and it is almost $\$ 5.3$ million, Table. 5 displays the cash flow of the project.

Table 5. Cash flow for whole system

\begin{tabular}{|c|c|c|c|c|c|c|}
\hline Component & Capital & Replacement & O\&M & Fuel & Salvage & Total \\
\hline PV & $\$ 22,000,000$ & $\$ 4,801,798$ & $\$ 7, \mathbf{0 3 0 , 8 5 0}$ & $\$ 0$ & $-\$ 2,691,138$ & $\$ 31,141,516$ \\
\hline GE 1.5sl & $\$ 24,000,000$ & $\$ 9,388,471$ & $\$ 1,303,903$ & $\$ 0$ & $-\$ 1,747,492$ & $\$ 32,944,882$ \\
\hline Generator 1 & $\$ 3,000,000$ & $\$ 0$ & $\$ 17,430,114$ & $\$ 6,135,402$ & $-\$ 276,803$ & $\$ 26,288,714$ \\
\hline Generator 2 & $\$ 600,000$ & $\$ 186,012$ & $\$ 10,607,636$ & $\$ 3,676,527$ & $-\$ 51,819$ & $\$ 15,018,354$ \\
\hline $\begin{array}{l}\text { Vision } \\
\text { 6FM200D }\end{array}$ & $\$ 6,400,000$ & $\$ 25,889,880$ & $\$ 10,226,691$ & $\$ 0$ & $-\$ 466,840$ & $\$ 42,049,736$ \\
\hline Converter & $\$ 2,000,000$ & $\$ 834,531$ & $\$ 1,278,336$ & $\$ 0$ & $-\$ 155,333$ & $\$ 3,957,535$ \\
\hline System & $\$ 58,000,000$ & $\$ 41,100,692$ & $\$ 47,877,528$ & $\$ 9,811,929$ & $-\$ 5,389,424$ & $\$ 151,400,704$ \\
\hline
\end{tabular}

\section{CAPITAL COST}

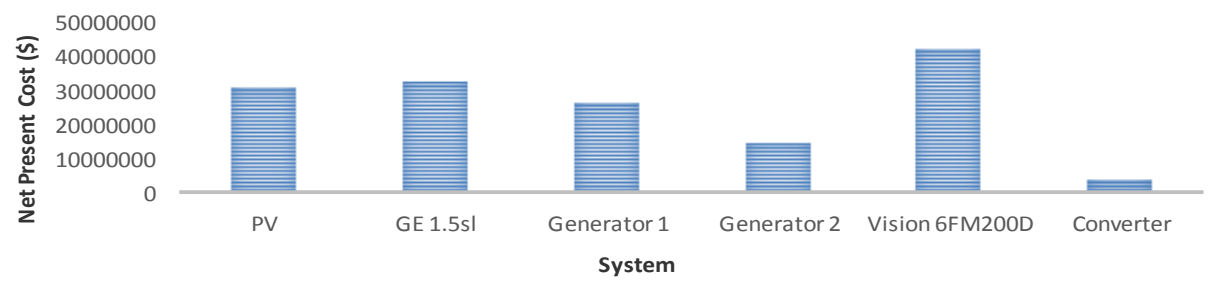

Figure 11. Capital Cost for the component.

\section{SOFTWARE SIMULATION TECHNIQUE}

HOMER software uses to exemplary probable mixed systems. The required data for this software includes modules specifications, meteorological data, electrical loads, and the costs. HOMER produces optimizations results for many of possible HRES and categories them based on lower 
net present cost. As HOMER duplications optimization procedure for individually value of input, it is potential to examine the effect of adaptable inputs like the properties of variance wind speed or solar energy [26]. Thought examination has been done by using HOMER to revision the effects of variables like fuel price, wind speed, and solar radiation. HOMER results including the Net Present Cost (NPC) or Net Present Value (NPV), Cost Of Energy (COE) and also contains Renewable Fraction (RF). Table 6 exposed the search scope in HOMER to get outputs, these outputs should be measured to estimate and compare different system configurations. Table 7 shown emission analysis that is completed by HOMER, proofs to emission lessening due to renewable penetration.

\section{Table 6}

\begin{tabular}{|c|c|c|c|c|c|c|}
\hline & PV Array & GE 1.5sl & Gen1 & Gen2 & Battery & Converter \\
\hline & $(\mathrm{kW})$ & (Quantity) & $(\mathrm{kW})$ & $(\mathrm{kW})$ & (Strings) & $(\mathrm{kW})$ \\
\hline 1 & 250 & 1 & 0 & 0 & 5 & 1,000 \\
\hline 2 & 500 & 2 & 2,000 & 250 & 10 & 2,000 \\
\hline 3 & 1,000 & 3 & 4,000 & 500 & 20 & 5,000 \\
\hline 4 & 3,000 & 5 & 6,000 & 1,000 & 30 & 10,000 \\
\hline 5 & 6,000 & 7 & 6,500 & 1,200 & 50 & 14,000 \\
\hline 6 & 12,000 & 10 & 6,750 & 1,250 & 100 & 16,000 \\
\hline 7 & 15,000 & 12 & 6,850 & 1,350 & 150 & \\
\hline 8 & 17,000 & 14 & & 1,370 & 250 & \\
\hline 9 & 17,500 & & & & 300 & \\
\hline 10 & 18,000 & & & & 320 & \\
\hline 11 & 22,000 & & & & 330 & \\
\hline 12 & 22,500 & & & & & \\
\hline
\end{tabular}

Search Space Categories

Table 7. System total emission per year:

\begin{tabular}{|l|l|}
\hline Pollutant & Emissions (kg/yr) \\
\hline Carbon dioxide & $1,850,558$ \\
\hline Carbon monoxide & 6,236 \\
\hline Unburned hydrocarbons & 691 \\
\hline Particulate matter & 470 \\
\hline Sulfur dioxide & 4,888 \\
\hline Nitrogen oxides & 55,648 \\
\hline
\end{tabular}

\section{Optimization Using ACO}

Ant colony optimization (ACO) is a technique for optimization that was presented in 1990s by Marco Dorrigo and his associates.

The improvement of this technique was stimulated by the consideration of ant societies. After numerous observations, it has been realized that the larger is the number of colonies using a definite path for finding food, the larger the possibility that the same trail will be utilized in future.

Some scientists considered such behavior and exposed a key point that the attendance of an ant specific pheromone is used to mark a trail. The smell of the pheromone is disappearing and, as a consequence, if a path is not utilized any more, its smell will get weaker. Thus, the probability of 
this path to be used in future will decline. The best passageway (it can also be called as "straight path") to the food in the planned application is the highest possible value of presentation index in an optimization procedure. [27]

Ant colonies, and more generally social insect civilizations, are distributed systems that, in spite of the ease of their people, present a highly structured social organization. AS a result of this organization, ant colonies can achieve complex tasks which in some cases far exceed the separate capabilities of a single ant. [28]

Consequently, we will use the same hybrid system components to can make compression between the two optimization methods in this approach.

\section{1) ACO Simulation Technique}

We simulate for each source of the hybrid network in Matlab as a bag with deferent rates to make random choose for getting the best NPC.Virtual trail accumulated on path segments between the bags, the path selected at random based on amount of "trail" present on possible paths from starting bags which selected randomly.

Ant reaches next bag, selects next path, the Ant continues until reaches last bag in the tour, the tour is analyzed for optimality of NPC.And then next ant start the tour until reaches for the last Ant. The program make a comparisons for all tour path of each Ant to get the best NPC.

$$
N P C=\sum_{t=0}^{T}\left(\frac{C t}{(1+i) t}-C o\right)
$$

$\mathrm{C}_{\mathrm{t}}=$ net cash inflow during the period $\mathrm{t} / \mathrm{C}_{\mathrm{o}}=$ total capital costs

$\mathrm{i}=$ interest rate $/ \mathrm{t}=$ number of time periods $\mathrm{T}=$ the project period

Ant will move from bag $i$ to bag $j$ with probability

$$
P i j=\frac{\left(\tau i j^{\alpha}\right)\left(\eta i j^{\beta}\right)}{\Sigma\left(\tau i j^{\alpha} * \eta i j^{\beta}\right)}
$$

$\tau i, j:$ is the amount of pheromone on edge $i, j$

$\alpha$ : is a parameter to control the influence of $\tau i, j$

$\eta \mathrm{i}, \mathrm{j}:$ is the desirability of edge $\mathrm{i}, \mathrm{j}$ (typically $1 / \mathrm{di}, \mathrm{j}$ )

$\beta \quad$ : is a parameter to control the influence of $\eta \mathrm{i}, \mathrm{j}$

2) The Results

A) We will run the program with constant number of iteration and change each time the number of ants and will notice the NPC results for each trail.

Max It $=$ Maximum Number of iteration $=300$,

\begin{tabular}{|l|l|l|}
\hline \multicolumn{1}{|c|}{ Item } & \multicolumn{1}{c|}{ No. } & \multicolumn{1}{c|}{ Indication } \\
\hline Iteration & $\mathbf{3 0 0}$ & Number \\
\hline Ants & $\mathbf{4 0}$ & Number \\
\hline Best Cost & $\mathbf{\$ 1 6 7 , 1 9 2 , 8 6 9}$ & $\mathbf{\$}$ \\
\hline PV & 1,674 & KW \\
\hline Wind & 3,070 & KW \\
\hline Converter & 5,808 & KW \\
\hline Batteries & 1,226 & KW \\
\hline Generator 1 & 506 & KW \\
\hline Generator 2 & 87 & KW \\
\hline
\end{tabular}

I. nAnt $=$ Number of Ants $=40$, 
II. nAnt=Number of Ants= 100,

\begin{tabular}{|l|l|l|}
\hline \multicolumn{1}{|c|}{ Item } & \multicolumn{1}{c|}{ No. } & \multicolumn{1}{c|}{ Indication } \\
\hline Iteration & $\mathbf{3 0 0}$ & Number \\
\hline Ants & $\mathbf{1 0 0}$ & Number \\
\hline Best Cost & $\mathbf{\$ 1 3 5 , 6 6 1 , 3 5 6}$ & KW \\
\hline PV & 653 & KW \\
\hline Wind & 2,472 & KW \\
\hline Converter & 5,681 & KW \\
\hline Batteries & 3,107 & KW \\
\hline Generator 1 & 196 & KW \\
\hline Generator 2 & 84 & \\
\hline
\end{tabular}

\begin{tabular}{|l|l|l|}
\hline \multicolumn{1}{|c|}{ Item } & \multicolumn{1}{c|}{ No. } & \multicolumn{1}{c|}{ Indication } \\
\hline Iteration & $\mathbf{3 0 0}$ & Number \\
\hline Ants & $\mathbf{2 0 0}$ & Number \\
\hline Best Cost & $\mathbf{\$ 1 2 9 , 9 7 4 , 6 7 1}$ & \$ \\
\hline PV & 995 & KW \\
\hline Wind & 2,335 & KW \\
\hline Converter & 7,744 & KW \\
\hline Batteries & 2,409 & KW \\
\hline Generator 1 & 161 & KW \\
\hline Generator 2 & 38 & KW \\
\hline
\end{tabular}

III. nAnt=Number of Ants $=200$,

nAnt=Number of Ants= 300,

\begin{tabular}{|l|l|l|}
\hline \multicolumn{1}{|c|}{ Item } & \multicolumn{1}{c|}{ No. } & \multicolumn{1}{c|}{ Indication } \\
\hline Iteration & $\mathbf{3 0 0}$ & Number \\
\hline Ants & $\mathbf{3 0 0}$ & Number \\
\hline Best Cost & $\mathbf{\$ 1 2 1 , 4 2 4 , 3 0 4}$ & \$ \\
\hline PV & 1,931 & KW \\
\hline Wind & 1,571 & KW \\
\hline Converter & 6,352 & KW \\
\hline Batteries & 2,695 & KW \\
\hline Generator 1 & 88 & KW \\
\hline Generator 2 & 16 & KW \\
\hline
\end{tabular}


IV. nAnt=Number of Ants= 500,

\begin{tabular}{|l|l|l|}
\hline \multicolumn{1}{|c|}{ Item } & \multicolumn{1}{c|}{ No. } & \multicolumn{1}{c|}{ Indication } \\
\hline Iteration & $\mathbf{3 0 0}$ & Number \\
\hline Ants & $\mathbf{5 0 0}$ & Number \\
\hline Best Cost & $\mathbf{\$ 1 2 4 , 3 4 9 , 0 7 1}$ & \$ \\
\hline PV & 2,070 & KW \\
\hline Wind & 1,909 & KW \\
\hline Converter & 6,291 & KW \\
\hline Batteries & 1,811 & KW \\
\hline Generator 1 & 97 & KW \\
\hline Generator 2 & 63 & KW \\
\hline
\end{tabular}

THE FINAL RESULTS

\begin{tabular}{|c|c|c|}
\hline Iteration & Ants & Net Present Cost \\
\hline \multirow{4}{*}{300} & 40 & $\$ 167,192,869$ \\
\cline { 2 - 3 } & 100 & $\$ 135,661,356$ \\
\cline { 2 - 3 } & 150 & $\$ 128,970,102$ \\
\cline { 2 - 3 } & 200 & $\$ 129,974,671$ \\
\cline { 2 - 3 } & 300 & $\$ 121,424,304$ \\
\cline { 2 - 3 } & 400 & $\$ 123,032,994$ \\
\cline { 2 - 3 } & 500 & $\$ 124,349,071$ \\
\cline { 2 - 3 } & 1000 & $\$ 126,124,816$ \\
\hline
\end{tabular}

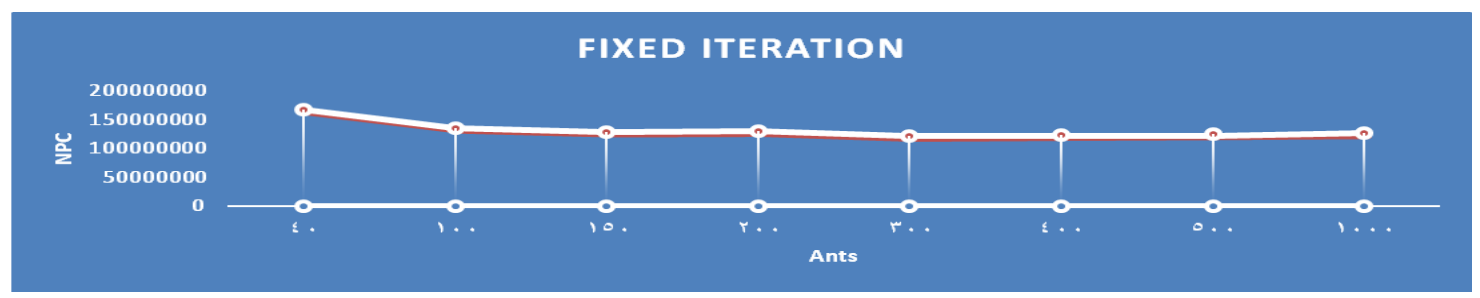

Fig 12. Fixed Iteration

B) We will run the program with constant number of Ants and change each time the number of MaxIt and will notice the NPC results for each trail also.

$\mathrm{n}$ Ant $=$ Number of ants $=300$.

I.

Max It=Maximum Number of Iteration=100.

\begin{tabular}{|l|l|l|}
\hline \multicolumn{1}{|c|}{ Item } & \multicolumn{1}{|c|}{ No. } & \multicolumn{1}{c|}{ Indication } \\
\hline Iteration & $\mathbf{1 0 0}$ & Number \\
\hline Ants & $\mathbf{3 0 0}$ & Number \\
\hline Best Cost & $\mathbf{\$ 1 3 5 , 5 3 6 , 9 6 6}$ & \$ \\
\hline PV & 440 & KW \\
\hline Wind & 1,865 & KW \\
\hline Converter & 7,486 & KW \\
\hline Batteries & 1,772 & KW \\
\hline Generator 1 & 895 & KW \\
\hline Generator 2 & 30 & KW \\
\hline
\end{tabular}




\section{Max It=Maximum Number of Iteration=200.}

\begin{tabular}{|l|l|l|}
\hline \multicolumn{1}{|c|}{ Item } & \multicolumn{1}{c|}{ No. } & \multicolumn{1}{c|}{ Indication } \\
\hline Iteration & $\mathbf{2 0 0}$ & Number \\
\hline Ants & $\mathbf{3 0 0}$ & Number \\
\hline Best Cost & $\mathbf{\$ 1 2 5 , 0 1 8 , 5 4 5}$ & $\mathbf{\$}$ \\
\hline PV & 2,729 & $\mathrm{KW}$ \\
\hline Wind & 1,655 & $\mathrm{KW}$ \\
\hline Converter & 8,530 & $\mathrm{KW}$ \\
\hline Batteries & 1,654 & $\mathrm{KW}$ \\
\hline Generator 1 & 26 & $\mathrm{KW}$ \\
\hline Generator 2 & 1 & $\mathrm{KW}$ \\
\hline
\end{tabular}

III. Max It=Maximum Number of Iteration=400.

\begin{tabular}{|l|l|l|}
\hline \multicolumn{1}{|c|}{ Item } & \multicolumn{1}{c|}{ No. } & \multicolumn{1}{c|}{ Indication } \\
\hline Iteration & $\mathbf{4 0 0}$ & Number \\
\hline Ants & $\mathbf{3 0 0}$ & Number \\
\hline Best Cost & $\mathbf{\$ 1 2 6 , 6 5 3 , 7 2 6}$ & $\mathbf{\$}$ \\
\hline PV & 927 & KW \\
\hline Wind & 1,579 & KW \\
\hline Converter & 6,610 & KW \\
\hline Batteries & 2,941 & KW \\
\hline Generator 1 & 265 & KW \\
\hline Generator 2 & 75 & KW \\
\hline
\end{tabular}

IV. Max It=Maximum Number of Iteration=600.

\begin{tabular}{|l|l|l|}
\hline \multicolumn{1}{|c|}{ Item } & \multicolumn{1}{c|}{ No. } & \multicolumn{1}{c|}{ Indication } \\
\hline Iteration & $\mathbf{6 0 0}$ & Number \\
\hline Ants & $\mathbf{3 0 0}$ & Number \\
\hline Best Cost & $\mathbf{\$ 1 3 4 , 6 6 0 , 7 9 4}$ & $\mathbf{\$}$ \\
\hline PV & 375 & KW \\
\hline Wind & 2,826 & KW \\
\hline Converter & 7,319 & KW \\
\hline Batteries & 2,681 & KW \\
\hline Generator 1 & 251 & KW \\
\hline Generator 2 & 28 & KW \\
\hline
\end{tabular}

THE FINAL RESULTS

\begin{tabular}{|c|c|c|}
\hline Ants & Iteration & Net Present Cost \\
\hline \multirow{4}{*}{300} & 100 & $\$ 135,536,966$ \\
\cline { 2 - 3 } & 200 & $\$ 125,018,545$ \\
\cline { 2 - 3 } & 300 & $\$ 121,424,304$ \\
\cline { 2 - 3 } & 400 & $\$ 126,653,726$ \\
\cline { 2 - 3 } & 500 & $\$ 132,896,330$ \\
\cline { 2 - 3 } & 600 & $\$ 134,660,794$ \\
\hline
\end{tabular}




\section{FIXED ANTS}

$\$ 140,000,000$

$\$ 130,000,000$

$\$ 120,000,000$

$\$ 110,000,000$

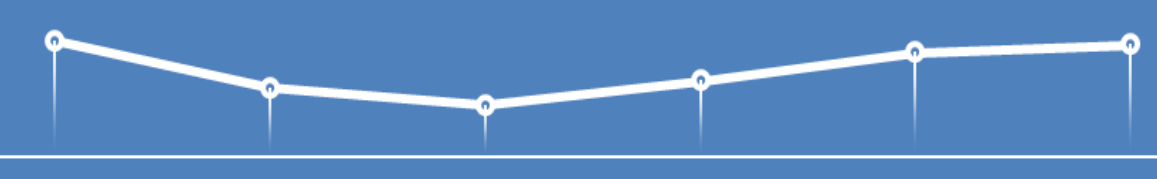

Itteration

Fig 13. Fixed Ants

We extract from the previous trails the best NPC is $\mathbf{\$ 1 0 2 , 7 5 4 , 2 0 6}$ for $\mathbf{n A n t}=\mathbf{3 0 0}$ and Max

It $=\mathbf{3 0 0}$.

\section{THE CONCLUSION}

Tumor of the global energy demand and environmental complications involving to fossil energy use have supported the widespread research on renewable energy apparatuses to exchange the traditional remains fuels. Mainly, hybrid systems that may be demarcated as a mixture of renewable and standby units or predictable energy sources change an effective solution to the competitions that the world faces in our time for sustainability dispute of energy source and environmental safety. The optimal sizing of these renewable energy recognized hybrid systems can significantly develop the economic and technical presentation of power supply as boosting the common use of such environment friendly sources.

Altered sizing approaches can be applied to reach an economically optimal design of hybrid renewable energy system. Therefore this approach presents the optimal design and theoretical studies for a renewable and conventional varied micro grid configuration. Numerous renewable energy possibilities such as wind turbine, solar photovoltaic (PV), generators and batteries are measured as possible options in the Micro Grid "MG" supply plan. Studies are carried out using the HOMER software and ACO method which make available a very effective tool for situation studies and policy analysis. Analysis description that the renewable and conventional mixed MG has the a lesser amount of Net Present Cost (NPC) and fairly minor carbon footprint, it is to be well-known that there is still greatly work to be done in standings of renewable energy and hybrid system development, subsequently of their high original capital and additional budgets, So Egypt nowadays try to decrease monopoly in the electrical market and encourage the investments in this market. Also the governmental feed-in tariffs will play an important role in the renewable energy system cost. This work also demonstrates that allowing a small amount of annual load to be left unmet makes the micro grid more cost-effective.

Finally, ACO optimization method was found to be a very helpful method for the micro grid development, sizing and dispatching more than HOMER program according to the pervious results.

\section{REFERENCES}

[1] World Health Organization (WHO) and United Nations Development Programmed (UNDP) (New York and Geneva). The Energy Access Situation in Developing Countries: A Review Focusing on the Least Developed Countries and Sub-Saharan Africa. 2009.1-142

[2] International Energy Agency Publications (IEA). World Energy Outlook, 2nd ed.; 2015.1200

[3] Qoaider L, Steinbrecht D. Photovoltaic systems: a cost competitive option to supply energy to off-grid agricultural communities in arid regions. Applied Energy 2010. 427-435

[4] Ma T, Yang H, Lu L. Feasibility study and economic analysis of pumped hydro storage and battery storage for a renewable energy powered island. Energy Conversion and Management; 2014. 387-397 
[5] Kaldellis JK, Zafirakis D, Stavropoulou V, Kaldelli E. Optimum wind- and photovoltaicbased stand-alone systems on the basis of life cycle energy analysis. Energy Policy 2012. 345357

[6] Bajpai P, Dash V. Hybrid renewable energy systems for power generation in stand-alone applications: a review. Renewable Sustainable Energy Rev 2012. 2926-2939

[7]Kaldellis JK, Kavadias KA, Koronakis PS. comparing wind and photovoltaic stand-alone power systems used for the electrification of remote consumers. Renewable Sustainable Energy Rev 2007. 401-425

[8] Yang H, Wei Z, Chengzhi L. Optimal design and techno-economic analysis of a hybrid solarwind power generation system. Applied Energy 2009; 86:163-9.

[9] Kapsali M, Anagnostopoulos JS, Kaldellis JK. Wind powered pumped-hydro storage systems for remote islands: a complete sensitivity analysis based on economic perspectives. Applied Energy 2012. 614-628

[10] Zhao B, Zhang X, Li P, Wang K, Xue M, Wang C. Optimal sizing, operating strategy and operational experience of a stand-alone microgrid on Dongfushan Island. Applied Energy 2014. 1656-1666

[11] Bernal-Agustín JL, Dufo-López R. Simulation and optimization of stand-alone hybrid renewable energy systems. Renewable Sustainable Energy Rev 2009. 2111-2118

[12 ]Kaldellis JK, Zafirakis D. Optimum sizing of stand-alone wind-photovoltaic hybrid systems for representative wind and solar potential cases of the Greek territory. J Wind EngIndAerodyn 2012. 1577-1587

[13] Yang H, Zhou W, Lu L, Fang Z. Optimal sizing method for stand-alone hybrid solar-wind system with LPSP technology by using genetic algorithm. Solar Energy 2008. 354-367

[14] Kaldellis JK, Zafirakis D, Kavadias K. Minimum cost solution of wind- photovoltaic based stand-alone power systems for remote consumers. Energy Policy 2012. 105-117.

[15] Lujano-Rojas JM, Dufo-López R, Bernal-Agustín JL. Optimal sizing of small wind/battery systems considering the DC bus voltage stability effect on energy capture, wind speed variability, and load uncertainty. Applied Energy 2012. 404-412

[16] Chen H-C. Optimum capacity determination of stand-alone hybrid generation system considering cost and reliability. Applied Energy 2013. 155-164

[17] Connolly D, Lund H, Mathiesen BV, Leahy M. A review of computer tools for analysing the integration of renewable energy into various energy systems. Applied Energy 2010. 1059-1082

[18] Luna-Rubio R, Trejo-Perea M, Vargas-Vázquez D, Ríos-Moreno GJ. Optimal sizing of renewable hybrids energy systems: a review of methodologies. Solar Energy 2012. 1077-1088

[19] Lambert T, Gilman P, Lilienthal P. Micropower system modeling with homer. Integration of alternative sources of energy. John Wiley \& Sons, Inc.; 2006. 1-40

[20] Maheri A. Multi-objective design optimization of standalone hybrid wind-PV-diesel systems under uncertainties. Renewable Energy 2014. 650-661

[21] Bonabeau, E., Dorigo, M., \& Theraulaz, G.Swarm Intelligence: From Natural to

Artificial Systems. Oxford University Press. . (1999).1-9

[22] Dorigo, M., \& Maniezzo, V. The Ant System: optimization by a colony of cooperating agents. IEEE Transactions on Systems, Man, and Cybernetics, (1996). 1-13.

[23] Wind finder forecasting e-magazine, Egypt, Cairo region, first edition 2017.197-201

[24] Saeed Mansour, Optimum Design Of On Grid PV System Using Tracking System.

International journal of scientific and technology research volume 4, issue 05, May2015 50-57

[25] Rehman S, Al-Hadhrami LM. Study of a solar PV-diesel-battery hybrid power system for a remotely located population near Rafha, Saudi Arabia. Energy2010; 35:49-95.

[26] Shafiullah GM, Amanullah MTO, Shawkat Ali ABM, Jarvis D, Wolfs P. Prospects of renewable energy e a feasibility study in the Australian context. Renew Energy 2012; 39:183-97.

[27]Mehmet Uzunoglu,Ozan Erdnic, Optimum design of hybrid renewable energy systems: Overview of different approaches, Research Gate 2011. 28.33

[28] Marco Dorigo, Mauro Birattari, , Thomas St"utzle, Artificial Ants as a Computational Intelligence Technique, Université Libre de Bruxelles IRIDIA,2006.1-14 